\title{
Indivíduos, instituições e desenvolvimento econômico
}

\author{
Aline Zulian* \\ Solange Regina Marin** \\ Paulo Ricardo Feistel***
}

\begin{abstract}
Resumo: O conceito para desenvolvimento econômico não possui um consenso universal. No entanto, sabe-se que as instituições são parte do desenvolvimento, assim como os indivíduos. Inicia-se esta análise com base na definição conceitual proposta por Amartya Sen, que considera o desenvolvimento econômico com base no exercício das capacitações individuais. Seguindo esta corrente de pensamento, objetiva-se verificar qual a influência das instituições no comportamento dos indivíduos e, também, relacionar as instituições e os indivíduos com o desenvolvimento econômico. Destacase que a influência das instituições no comportamento individual será analisada na visão de Douglass C. North e de Geoffrey M. Hodgson. Percebeu-se, ao fim, que os comportamentos dos indivíduos são moldados pelas instituições preexistentes e que a definição de Sen para desenvolvimento está relacionada aos indivíduos e também às instituições, de modo a perceber que estes três elementos: indivíduos, instituições e desenvolvimento econômico estão diretamente interligados.
\end{abstract}

Palavras-chave: Desenvolvimento, Indivíduos, Instituições.

Classificação JEL: B52; O10; O12.

\footnotetext{
* Mestre pelo Programa de Pós-Graduação em Economia e Desenvolvimento da Universidade Federal de Santa Maria (PPGE\&D-UFSM). E-mail: alinezulian@hotmail.com

**Professora Doutora do Departamento de Economia e do Programa de Pós-Graduação em Economia e Desenvolvimento da Universidade Federal de Santa Maria (PPGE\&D-UFSM). E-mail: solremar@yahoo.com.br

*** Professor Doutor do Departamento de Economia e do Programa de Pós-Graduação em Economia e Desenvolvimento da Universidade Federal de Santa Maria (PPGE\&D-UFSM). E-mail: prfeistel@yahoo.com.br
} 


\section{Introdução}

O termo "desenvolvimento econômico" abrange inúmeras definições. Sen (1988) deixa claro que conceituar desenvolvimento não é uma tarefa fácil, mas que este não pode ser confundido com crescimento econômico. Partindo desta análise, Sen (1983) considera o desenvolvimento econômico como resultado da ampliação das capacitações humanas.

Outro elemento fundamental relacionado ao desenvolvimento econômico é a existência e a função das instituições. Além disso, é importante destacar que a teoria institucionalista traz à tona, assim como a definição de desenvolvimento de Sen, a figura do indivíduo. No entanto, a concepção da Nova Economia Institucional (NEI) difere em alguns pontos da visão dos velhos institucionalistas e dos neo-institucionalistas. O problema central é a existência ou não, com base em Douglass C. North e Geoffrey M. Hodgson, de influência das instituições no comportamento individual e no desenvolvimento econômico proposto por Sen.

Desta forma, o objetivo do artigo é verificar a influência das instituições no comportamento dos indivíduos e, também, relacionar as instituições e os indivíduos com o desenvolvimento econômico. A influência das instituições no comportamento individual será analisada com base em North, que mais se aproxima da NEI, e Hodgson, que é classificado como um neo-institucionalista. A definição de desenvolvimento econômico será baseada em Amartya Sen.

Para alcançar os objetivos deste estudo, será realizada, após esta introdução, uma exposição do conceito de desenvolvimento econômico na visão de Amartya Sen. Então, serão elencadas as visões institucionalistas de North e Hodgson com foco no comportamento dos indivíduos. Por fim, serão feitas breves considerações finais a respeito das duas linhas de pensamento, juntamente com a definição de desenvolvimento econômico sugerida neste trabalho.

\section{Desenvolvimento econômico na visão de Amartya Sen}

Os teóricos tradicionais sobre crescimento e desenvolvimento (como Rosenstein-Rodan, Nurkse, Lewis, etc.) consideravam que as medidas adotadas para alavancar o crescimento econômico seriam as formas para proporcionar o desenvolvimento econômico (Sen, 1988). No entanto, evidências empíricas comprovaram que, em muitos países, apesar de existir alto índice de crescimento econômico per capita (medido pelo Produto Interno Bruto, PIB, per capita), a expectativa de vida, por exemplo, era inferior ao dos países com menor valor do PIB (Sen, 1988). Assim, não é correto igualar a definição de desenvolvimento à de crescimento, mas, conforme Sen (1983), deve-se considerar o crescimento como parte do desenvolvimento econômico.

Apesar da teoria do desenvolvimento tradicional identificar os fatores que levam ao crescimento econômico, ela não apresenta as causas que levam ao crescimento econômico (Sen, 1983). Ou seja, a teoria tradicional acaba concentrando-se apenas na mensuração do crescimento da renda e ignorando 
outras questões de âmbito social, como aquelas relacionadas aos funcionamentos das pessoas e às capacitações individuais (Sen, 1983).

Assim, na visão de Sen (1983), o crescimento econômico não pode ser visto como um fim em si mesmo ("produzir riqueza"). Sen (1990), então, define o desenvolvimento como a expansão das capacitações, considerando que a vida humana constitui-se de um conjunto de "ser e fazer", chamado de funcionamentos ("doing and being").

Os funcionamentos são definidos como as conquistas do indivíduo, aquilo que ele consegue ser ou fazer; enquanto que as capacitações refletem as combinações e as realizações dos funcionamentos. Ou seja, "capacitações refletem a liberdade pessoal para escolher entre diferentes maneiras de viver" (Sen, 1990, p. 44, tradução nossa).

Sendo assim, os funcionamentos podem ser vistos de diferentes perspectivas, variando de uma pessoa para outra e conforme as condições de liberdade/privação de cada indivíduo, da existência e do acesso aos serviços (como de educação e de saúde) e entre outros elementos presentes no ambiente onde o indivíduo está inserido (Sen, 1990).

Esta visão pluralista das capacitações, de acordo com Sen (1990), indica que por mais que os indivíduos tenham funcionamentos iguais nem todos possuem as mesmas capacitações. O exemplo apresentado por Sen (1990) foi o caso de duas pessoas possuírem o mesmo funcionamento, como o ato de jejuar. No entanto, uma delas pode jejuar pelo simples fato de optar por não alimentarse devido a motivos individuais, religiosos, etc. Enquanto que a outra pessoa pode não ter a chance de escolher entre alimentar-se ou não, pelo fato de viver na miséria.

Sen (2009) destaca o papel das instituições afirmando que estas podem influenciar diretamente na vida das pessoas, de maneira que elas facilitem o exercício das habilidades individuais ao analisar os valores e as prioridades que devem ser considerados. Sen (2009) preocupa-se com o foco dado às instituições ao invés de dar importância ao que elas realmente se propõem a fazer, como seria o caso da promoção da justiça social. Ou seja, o exercício das capacitações pode depender tanto, por exemplo, da cultura e da educação recebida no âmbito familiar, quanto do serviço educacional fornecido pela região em que as pessoas estão inseridas.

Para Sen (1990), mesmo que os fins sejam iguais para as pessoas, as capacitações em transformar os bens primários ou a liberdade em realizações são diferentes, não sendo possível fazer uma comparação interpessoal e basear-se somente, por exemplo, numa divisão que aparentemente seja justa (igualitária).

As instituições e as regras existem e são importantes para influenciar nos acontecimentos, mas, para Sen (2009), a realidade vai muito além de uma imagem organizacional ou formal, inclui a vida que as pessoas escolhem ou não viver (liberdade de escolha). Assim, instituições e regras, por mais importantes que sejam, precisam ter suas funções analisadas de forma mais ampla, ligada ao contexto e local em que surgem, sendo que uma boa idéia para isto, ao observar os perigos das instituições que são puramente focadas em processos, é o debate 
público (Sen, 2009).

A natureza da sociedade que resulta de um conjunto de instituições também depende de características que Sen (2009, p. 6) define como "não institucionais", tais como os comportamentos individuais e as suas interações sociais. Isto foi chamado de "instituições informais" por North (2003), que será elencado no próximo item.

\section{Instituições e indivíduos na visão de Douglass North}

A Nova Economia Institucional (NEI) retomou as discussões a respeito de um conjunto mais amplo de instituições, e não apenas sobre o mercado (Pessali e Dalto, 2010). Nesta linha de pensamento, as instituições surgem para reduzir as incertezas (o caso principal é a assimetria de informações) nas transações entre os indivíduos (Medeiros, 2001).

Investigou-se as ideias de Douglass North, uma vez que possui uma definição para "instituições" bastante conhecida e difundida na literatura (Pessali e Dalto, 2010). Para North (2003), as instituições existem para reduzir as incertezas, para dar uma boa continuidade aos negócios e resolver os problemas de maneira eficaz.

Um importante elemento desenvolvido por North (1990) é a diferenciação entre instituições formais e informais. As primeiras são compostas por regras formalizadas, leis, constituições, regulamentos, etc.; enquanto que as segundas compõem-se de normas informais oriundas do comportamento humano.

As instituições formais são equiparadas às regras preestabelecidas de um jogo, enquanto que as instituições informais resultam do comportamento humano. Desse modo, as instituições informais são mais complexas, uma vez que envolvem as heranças culturais e as crenças, que diferem de um indivíduo para outro (North, 2003). Para North (2003), a herança cultural é um dos elementos que molda a maneira como as escolhas são feitas e a forma como as sociedades e as instituições evoluem.

Conforme Medeiros (2001), a questão central para North é verificar se as instituições são o resultado dos comportamentos/preferências individuais com o objetivo de reduzir a incerteza presente nas relações, e identificar como essas instituições evoluem e interferem no funcionamento da economia. Assim, North (1990) destaca que as instituições são criadas pelos indivíduos e estes também as modificam.

Apesar de North (2003) apontar falhas ao pensamento neoclássico, pois considera a existência de incertezas e que os indivíduos não possuem visão completa da realidade, o que faz com que as instituições sejam criadas; em outros pontos, a tendência de continuidade aos supostos da teoria neoclássica fica evidente. Isto se refere principalmente ao pressuposto neoclássico mantido por North sobre o "individualismo metodológico", em que os indivíduos e suas interações irão justificar o surgimento das instituições, pois, para este autor, "cada pessoa interpreta o mundo de acordo com seu modelo mental" (Pessali e Dalto, 2010, p. 16). 
Esta concepção oriunda de North sofre críticas, uma vez que ele não explica como estes "modelos mentais" individuais surgiram e como os indivíduos isolados poderiam ter semelhanças de pensamentos entre si (Pessali e Dalto, 2010). Ou seja, "ao assumir a existência dos modelos mentais dos indivíduos, a versão "individualista" se apóia, por exemplo, em uma instituição previamente existente, a linguagem, para poder explicar como um modelo mental pode ser disseminado ou apreendido" (Pessali e Dalto, 2010, p. 16). É neste sentido que reside uma das críticas à North, pois ele não considera essas instituições preexistentes e, por isto, defende a ideia de que são os indivíduos que irão influenciar as instituições, e não o contrário.

Outra linha de pensamento que investiga as instituições juntamente com os indivíduos é a neo-institucionalista. Geoffrey M. Hodgson é "considerado pelos especialistas o principal teórico da economia evolucionista da atualidade" (Veiga, 2008) e é um dos representantes desta corrente neo-insticionalista.

\section{Instituições e indivíduos na visão de Geoffrey Hodgson}

Contrapondo a teoria neoclássica e os institucionalistas de cunho mais neoclássico, que defendem a ideia de que o comportamento dos indivíduos baseiase no "individualismo metodológico", o neo-institucionalismo, que derivou seus trabalhos principalmente dos velhos institucionalistas, trata de instituições já preestabelecidas.

De acordo com Barbosa e Comim (2012), a NEI possui maior ênfase em arranjos de coordenação, em contrapartida, o velho institucionalismo detém-se nas mudanças institucionais e sociais, sem realizar juízo de valor sobre o que é gerado na interação entre instituições, indivíduo e sociedade.

Barcelos (2011), que investigou o comportamento humano na visão institucionalista, destacou que, enquanto que para os pensadores da NEI o comportamento dos indivíduos envolve o oportunismo e a racionalidade limitada, para os teóricos neo-institucionalistas, o indivíduo é o elemento central para analisar a sociedade e não é estático, seu comportamento está em constante mutação, e a instituição seria a ponte teórica entre o indivíduo e o agregado (sociedade).

Os neo-institucionalistas foram influenciados pelos velhos institucionalistas, principalmente por escritos de Veblen. Este descreve a evolução de uma sociedade em que, na fase predatória, as atividades cotidianas passam a assumir um maior caráter de proeza e este passa a ser o pensamento ideal dos homens. Troféus e títulos adquirem maior prestígio e passam a acirrar a competição entre os indivíduos; enquanto que o trabalho produtivo adquire um caráter desagradável em razão da indignidade pelo qual está relacionado (Veblen, 1983).

A luta sempre esteve presente na evolução cultural, no entanto, o que Veblen (1983) quer destacar é a existência de um hábito dominante de julgar os fatos do ponto de vista da luta (honrar essa prática). Veblen (1983) descreve que 
as instituições são hábitos e costumes rotineiros que estão ligados a um contexto histórico, como o caso da "classe ociosa" ${ }^{1}$ que apareceu juntamente com o início da propriedade.

Assim como o comportamento humano modifica-se com o passar do tempo, as instituições também são mutáveis (Veblen, 1983). Com base neste pensamento vebleniano, um dos autores neo-institucionalistas mais conhecidos é Geoffrey Hodgson. Para ele, "as instituições são sistemas duráveis de regras sociais estabelecidas e incorporadas e convenções que estruturam as interações sociais", sendo que estas dependem das ações e dos pensamentos individuais (Hodgson, 2003, p. 163, tradução nossa). Existe grande aceitação desta definição, sendo que alguns exemplos de instituições são: moeda, mercado, linguagem, leis, sistemas de pesos e medidas, maneiras de se portar à mesa, etc. (Hodgson, 2001).

As instituições ao mesmo tempo em que entram em confronto com os indivíduos também partem deles (Hodgson, 2003). Para o mesmo autor, todos os indivíduos nascem em um lugar onde já existem instituições, que foram concebidas pelo processo histórico, como é o caso da linguagem, que existe antes mesmo do indivíduo nascer.

O estudo de Menger, conforme Hodgson (2001), e de muitos neoinstitucionalistas analisa o surgimento de instituições de forma espontânea, via interação dos indivíduos que perseguem seus objetivos particulares. Menger (1981 apud Hodgson, 2001) faz sua análise partindo de um dado indivíduo para instituições emergentes ("de baixo para cima”), isto é, parte dos indivíduos em um "estado natural" em que não existem instituições. No entanto, "é esquecido que, no hipotético original "estado de natureza" do qual as instituições são vistas emergindo, um número importante de regras, instituições e normas culturais e sociais são já presumidas" (Hodgson, 2001, p. 102). Apesar de não considerar as instituições preexistentes, o próprio Williamson (1975 apud Hodgson, 2001, p. 102) cita que "no início havia mercados"; e Hodgson (2001) destaca que "o próprio mercado é uma instituição".

O que está sendo criticado por Hodgson (2001) é o fato de Menger e Williamson considerarem os indivíduos como "dados" em um ambiente inicial sem instituições. Para o autor, qualquer estudo deve levar em conta tanto os indivíduos quanto as instituições, ao mesmo tempo, num ambiente dinâmico, havendo um "ciclo de determinação inquebrantável". No entanto, isto não significa que indivíduos e instituições possuem mesmo caráter explicativo e ontológico, pois são caracterizados distintamente: "indivíduos são movidos por propósitos, instituições não o são, ao menos no mesmo sentido" (Hodgson, 2001, p. 104). Hodgson (2001) refere-se ao mecanismo de reprodução que difere entre os dois, e o fato das instituições sobreviverem muitas vezes por décadas, muito além do tempo de vida de um indivíduo.

Assim, uma nova análise deveria ser feita para passar a considerar a evolução das instituições num ambiente com instituições já existentes (Hodgson,

1 A instituição de uma classe ociosa resulta da discriminação, preestabelecida, entre diversas funções que são consideradas dignas ou indignas (Veblen, 1983), sendo que na sociedade em questão, o trabalho industrial, ou produtivo, era visto com desprezo. 
2001). Neste sentido, para o mesmo autor, os elementos do sistema podem evoluir, assim como as preferências individuais. E, apesar das instituições envolverem regras e restrições que aparentemente são "fixas" e poderem moldar as preferências individuais, a variação nas preferências pode possibilitar o aparecimento de instituições ou a superação de dificuldades das instituições que falham ao emergir (Hodgson, 2001).

Um elemento chave para o processo de mudanças comportamentais e institucionais é o hábito. Hodgson $(2001 ; 2003)$ diferencia o hábito dos indivíduos do comportamento, pois o primeiro surge da repetição da ação ou do pensamento ("propensão ao comportamento"), enquanto que o segundo é a ação propriamente dita.

Hodgson (2006) e também North (1990) destacam que as instituições podem restringir ações, mas também podem possibilitar a melhor escolha de possibilidades existentes. Hodgson (2006) exemplifica isto com: as regras de linguagem que permitiram a comunicação, as regras de trânsito que ajudaram na melhor organização e segurança do tráfego, etc.

As instituições estruturam as interações sociais, sendo que a durabilidade delas decorre exatamente do fato de elas possibilitarem a formação de expectativas estáveis sobre o comportamento dos outros indivíduos (Hodgson, 2006). As instituições, de acordo com Hodgson (2006), dependem dos pensamentos e das ações individuais, permitindo que exista um pensamento ordenado, impondo forma e consistência nas atividades exercidas pelos indivíduos.

Com isso, torna-se impossível analisar as instituições e o desenvolvimento econômico sem considerar o papel das chamadas "instituições informais". As instituições influenciam no desenvolvimento econômico exatamente pelo seu poder de reconstruir as preferências e comportamentos dos indivíduos (Pessali e Dalto, 2010). Desta forma, para Pessali e Dalto (2010, p. 24), a "concepção moderna de desenvolvimento se caracteriza justamente pela ampliação da liberdade das pessoas, o que inclui a ampliação dos recursos materiais que atendam as suas necessidades de sobrevivência e bem-estar".

\section{Considerações finais}

A tradicional teoria do desenvolvimento econômico, com foco no crescimento, incorpora o papel das instituições. Contudo, as maneiras como os indivíduos se comportam e se relacionam foi abstraída das análises mais tradicionais, diferente da abordagem deste artigo.

Apesar da distinção entre North, que considera que os indivíduos moldam as instituições, e Hodgson, que considera o contrário, os institucionalistas possuem grande relevância para o estudo dos indivíduos e do desenvolvimento. Além disso, tanto North quanto Hodgson consideram que as instituições podem ampliar e/ou restringir o comportamento individual.

A definição de Sen para desenvolvimento econômico incorpora o 
comportamento dos indivíduos através do exercício das capacitações, sendo estas moldadas pelas instituições e, desta maneira, assemelha-se com a corrente neoinstitucionalista. A relação entre as instituições e a definição de desenvolvimento proposta por Sen, está no exercício das capacitações, que difere de um indivíduo para outro em função das instituições informais e formais, como distinguido por North. E, além disto, essas instituições acabam influenciando nas capacitações individuais.

Esta relação entre instituições e desenvolvimento em Sen pode ser percebida quando o próprio autor diferencia funcionamentos de capacitações. Assim, o importante está em analisar a possibilidade ou não da realização das capacitações, isto é, na existência da liberdade dos indivíduos em ter o poder de optar entre um estilo de vida ou outro.

As instituições a priori, moldam os hábitos e os comportamentos dos indivíduos. Neste sentido, a ideia "de causação de cima para baixo" (das instituições para os indivíduos), de Hodgson, é condizente com a realidade, pois a análise deve sempre levar em conta as instituições já existentes, como a linguagem.

É fundamental analisar as instituições e o desenvolvimento econômico de forma agregada, uma vez que as primeiras são constituídas por indivíduos e o desenvolvimento econômico depende das capacitações destes. Por fim, o estudo dos comportamentos individuais no ambiente dinâmico deve ser pauta inicial de qualquer estratégia ou discussão política que envolva o desenvolvimento econômico, uma vez que o objeto de estudo entre as esferas econômica, social e política é comum: os indivíduos.

\section{Referências bibliográficas}

Barbosa, B. B.; Comim, F. V. (2012). O debate institucionalista e a inserção da moralidade. In: Encontro Nacional de Economia da ANPEC, 40, Porto de Galinhas, PE. Anais eletrônicos. URL: <www.anpec.org.br/...I/i5-686991855d77d a00ff5b166ba883ad08.doc>. Acesso em: 19 de julho de 2013.

Barcelos, O. (2011). O comportamento humano no pensamento institucionalista uma breve discussão. Século XXI, Santa Maria, v. 1, n. 1, p. 44-63.

Hodgson, G. (2001). A evolução das instituições: uma agenda para pesquisa teórica futura. Revista Econômica, Rio de Janeiro, v. 3, n. 1, p. 97-125.

Hodgson, G. (2003). The hidden persuaders: institutions and individuals in economic theory. Cambridge Journal of Economics, 27, p. 159-175.

Hodgson, G.(2006). What Are Institutions? Journal of Economic Issues, v. 40, n. 1, p. $1-25$.

Medeiros, C. A. de. (2001). Instituições, Estado e Mercado no Processo do Desenvolvimento Econômico. Revista de Economia Contemporânea, Rio de Janeiro, v. 5, n. 1, p. 49-76. 
North, D. C. (1990). Institutions, Institutional Change and Economic Performance. Cambridge: University Press.

North, D. C. (2003). The Role of Institutions in Economic Development. United Nations Economic Commission Europe, Geneva, Switzerland. Discussion Paper Series.

Pessali, H.; Dalto, F. (2010). A mesoeconomia do desenvolvimento: o papel das instituições. Nova Economia, Belo Horizonte, v. 20, n. 1, p.11-37.

Sen, A. (1983). Development: Which way now? The Economic Journal, v. 93, n. 372, p. 745-762.

Sen, A. (1988). The concept of development. Handbook of Development Economics, cap. 1, Harvard University: Elsevier Science Publishers.

Sen, A. (1990). Development as capability expansion. In: Grin, K.; Knight, J. (Eds.). Human development and the international development strategy for the 1990s, London: Macmillan, p. 41-58.

Sen, A. (2009). The idea of justice. Cambridge: Belknap Press.

Veblen, T. B. (1983). A teoria da classe ociosa: um estudo econômico das instituições. São Paulo: Abril Cultural.

Veiga, J. E. da. (2008). Darwinismo e ciências sociais: um diálogo possível. Entrevista com Geoffrey M. Hodgson. Estudos Avançados, n. 22, v. 63. 
